\title{
RAZÓN Y RACIONALIDADES, LA VERDAD Y SUS POSIBLES VERSIONES POSMODERNAS
}

\author{
Reason and Racionalities, Truth and Its Posible \\ Postmodern Versions
}

Christopher Dante Rojas Quispe*

\begin{abstract}
RESUMEN
La inoperancia de una razón moderna y tradicional en el mundo contemporáneo nos lleva a cuestionar los viejos parámetros desde los cuales se circunscribía a la verdad. Así, el declive de una razón moderna se verá reflejado desde los efectos de verdad a través del lente posmoderno. Cuestiones como la arbitrariedad de una razón omnisciente que aún desplaza sus tentáculos sobre las diversas áreas del pensamiento a pesar de que las racionalidades ganan cada vez más terreno, serán motivo de reflexión, ergo, una entrada transdisciplinar será el enfoque que más se adecúe a los propósitos del presente artículo.
\end{abstract}

\section{Palabras clave:}

Posmodernidad, razón, verdad, modernidad.

\begin{abstract}
The inoperativeness of a traditional and modern reason in the contemporary world leads us to question the old limits from which truth was delimited. Thus, the decline of a modern reason will be reflected on the effects of truth or its construction through the postmodern lens. Issues, such as the arbitrariness of an omniscient reason that still moves its tentacles over diverse areas of thinking, even though rationalities gain more ground, will be cause of reflection; as a result, a multidisciplinary entry will be the more suitable approach to reach the objectives of this article.
\end{abstract}

\section{Keywords:}

Postmodernity, reason, truth, modernity.

Universidad Nacional Mayor de San Marcos: christofercito@yahoo.es 


\section{Introducción}

En el mundo contemporáneo resulta por demás discutible continuar hablando de razón y verdad, máxime si los vientos actuales hacen hincapié en una ineludible mirada posmoderna a través de la cual atravesar cualquier problemática actual. Y es desde ahí precisamente que el presente artículo busca posibles explicaciones a partir de las posibilidades que ella abre. De modo que los dos ejes serán la vigencia de una razón moderna vinculada a la verdad en el panorama actual y las posibilidades que dentro de este la posmodernidad abre, esto es, racionalidades y efectos de verdad.

\section{Modernidad, razón y verdad}

La historia del pensamiento filosófico moderno se inició con René Descartes y lo que caracteriza a la racionalidad moderna es su deseo incontrolable de controlar lo circundante y el pensamiento, a saber, la res extensa y la res cogitans. Límites que delimitarían el acceso al conocimiento, léase su definición, delimitación y construcción.

El conocimiento entonces, entendido así, resulta de lo que la razón moderna determine pertinente $\mathrm{o}$, vale decir, de lo que sus propios límites le permitan elaborar. Esto quiere decir que podríamos interpretar a la razón moderna como el campo de acción otorgado por sus propios límites inmanentes. En ese sentido, sí habría un componente de construcción de conocimiento exteriorizado, toda vez que éste tendría lugar a partir de la razón y en aras de objetivar el mundo. Y es precisamente ahí donde la noción de verdad tiene lugar, dentro de la esfera de conocimiento delimitada por la razón y el entorno.

En los albores de los tiempos modernos, un sujeto racional y espiritual, inspirado en los moldes cartesianos y constituido en los siglos XVI y XVII, observaba una realidad que era exterior a sí mismo. Para eso, se apertrechaba con el poderoso instrumental de su razón o bien se volvía hacia dentro de sí mismo, pero esa indagación se efectuaba de la misma forma que la observación considerada exterior; es decir, utilizando idénticos métodos y herramientas. Todo sucedía como si una especie de luminosidad orientase su mirada veraz, comparable a una lente transparente y todopoderosa: la luz de la racionalidad humana, que penetraba en las cosas para comprenderlas. Esa mirada era capaz de captar la verdad del mundo tal y cómo éste era, siempre que lograse esquivar los engaños e ilusiones de lo sensible gracias a la limpidez de la razón. De esa forma, el sujeto podía aprehender la realidad exterior en su totalidad, y además de captarla estaba en condiciones de comprenderla y explicarla en su transparencia racional. (Sibilia, 2017, p. 118)

Como bien indica Paula Sibilia, las categorías estaban claramente definidas y establecidas y se daba por sentado que era así y nadie debía siquiera aventurarse a cuestionarlas. En suma: el carácter diáfano de la razón capaz de transparentar el mundo a la luz de su propia luminosidad interna, la preponderancia de lo interno frente a un mundo ordinario y corrupto por naturaleza. He ahí pues el relevo del mundo frente al (pre)dominio de la razón, como de todo lo que se le parezca, los sentidos, las experiencias sensibles y aquello que pudiera dar pie a signos de subjetividad, es decir, de independencia de la razón objetivante a ultranza, toda 
vez que eso supondría invertir la relación y desclasar a la razón superior de su sitial.

Subyace a todo este mecanismo racional el control de lo disperso, en otras palabras, habría un componente de dispersión fundamental en la fundamentación racional del conocimiento en la modernidad. El conocimiento se desborda y una racionalidad moderna busca parametrizarlo.

Es por eso que el centro de la reflexión en torno al conocimiento y su mecanismo de acción debiera estar puesto en lo que el conocimiento oculta al mostrar su conocimiento. Pero vemos que en la práctica no es así, más bien se tiende a hacer foco sobre lo mostrado y no sobre lo oculto que resulta de dicha mostración. Luego, si se determina la verdad dentro del contexto moderno racional, debiera estudiarse en tanto signo de ocultamiento de aquello que una verdad mostrada según una racionalidad moderna busca controlar y en esa medida ocultar.

Y como bien señala Foucault en La hermenéutica del sujeto, lo que diferencia al mundo antiguo del moderno es la relación del sujeto en torno a la verdad, es decir, el acceso a la verdad por parte de él. Mientras que el primero suponía un viraje ético del sujeto, aspiración a la verdad a partir de una transformación de su ser, el segundo privilegió una verdad que lo ilumina desde siempre y que, en esa medida, lograría un cambio en él. Subyace a las reflexiones foucaultianas la relación ambivalente sujeto cognoscente y objeto del conocimiento. Remitámonos a este respecto a la carpeta inédita del mencionado seminario del propio autor.

1.- ¿Se puede tener acceso a la verdad sin poner en juego el ser mismo del sujeto que accede a ella?
¿Podemos tener acceso a la verdad sin pagarlo con un sacrificio? ¿Puede tener el sujeto, tal como es, acceso a la verdad? Descartes responderá a esta pregunta con un sí; Kant la contestará también de manera tanto más afirmativa cuanto que es restrictiva: lo que hace que el sujeto, tal como es, pueda conocer, es también lo que hace que no pueda conocerse a sí mismo (Foucault, 2012, p. 494)

Vemos pues las implicancias del conocimiento de la verdad en relación al sujeto, el inextricable vínculo entre asirla y hacerse o (des)hacerse de él. El acercarse a ella y el distanciarse de uno mismo. La transformación inevitable tanto de la adquisición de la verdad como de aquel que la pretende es una consecuencia inmediata, de ahí la necesidad de (de) limitarlos claramente. Es en ese intento de clasificación de lo que es la verdad, su aprehensión y la variación que el sujeto manifestará, el lugar donde los vínculos con un poder occidental se hacen visibles.

La verdad, en ese sentido, sería una medida de controlar el desborde connatural del conocimiento. Recordemos lo que Jean-Françoise Lyotard dice al respecto: "Posmoderno será comprender según la paradoja del futuro (post) anterior (modo)" (Lyotard 2004, p. 73). En efecto, si el estadio primero fue el caos, el desorden, lo arbitrario, cobra sentido entonces una modernidad que busque (re)organizar y racionalizar lo anterior, ergo, la posmodernidad necesariamente sería anterior a la modernidad, precisamente porque ésta (re)presenta la sistematización, el intento de establecer cierto orden en aquello que la antecedió.

Sin embargo, no podemos referirnos a Descartes sin hacer un flashback hacia 
Platón, pues bien, la filosofía platónica propugnaba que recordar es traer de vuelta, llevar al presente lo que fue, lo pretérito. Aquello que ya poseíamos antes de llegar al mundo, pero que perdimos no bien arribamos a aquel.

En la actualidad, en el mundo contemporáneo, sin embargo, la noción de actualidad, concepto explotado por el periodismo y los medios masivos, reconfigura el panorama del conocimiento y de la verdad. Así, por un lado, el pensar no es una cualidad que destaque entre el común de las personas, en contraposición con un determinismo de la inmediatez propugnado y promovido por las nuevas tecnologías de la información.

Estudiar, pues equivale hoy a capacitarse del modo más rápido, operativo e instrumental posible y darle a la memoria un trabajo, las más de las veces, mecánico y de corto aliento, dado el carácter abrumadoramente facilitador, digámoslo así, que hoy recibe el aprendiz de los soportes electrónicos o del llamado disco duro (Hevia, 2016, p. 123).

Efectivamente, pensar, en el sentido tradicional del término, supondría un esfuerzo sobre humano, venido a menos, casi sospechoso, toda vez que la capacidad analítica es la menos requerida en las instituciones educativas. Por un lado, los profesores se concentran en las llamadas competencias y, por otro, la barahúnda de discursos mediáticos publicitarios y la cantidad de información como la dependencia de las nuevas herramientas tecnológicas, han creado no solo una generación de adictos, sino también de cuerpos dóciles capaces de reaccionar ante el menor estímulo, lo cual supone una ligereza de materia gris y una liviandad corpórea que raya con la de un zombi.

Pero vayamos por partes, en primer lugar, conocer como lo entendía Platón, noción que luego Descartes retomaría al igual que Bacon, cada uno para justificar sus teorías del conocimiento, supuso un optimismo respecto a la verdad como susceptible de ser aprehendida en tanto manifiesta.

\section{El nacimiento de la ciencia moderna y de la tecnología moderna estuvo inspirado por ese optimismo epistemológico cuyos principales voceros fueron Bacon y Descartes. Ellos afirmaban que nadie necesita apelar a la autoridad en lo que concierne a la verdad, porque todo hombre lleva en sí mismo las fuentes del conocimiento" (Popper, 1994, p. 26).}

En efecto, para los tres conocer era re-conocer, un revivir lo pasado, lo ya conocido. Luego, el conocimiento y con ello el pensar, suponía un tipo de olvido que justificara el recuerdo de precisamente aquello que había sido dejado de lado. Entonces para conocer era necesario olvidar y recordar lo olvidado. Segundo, conocer, demás está decirlo, suponía cierta perduración y constancia de las ideas, esto es, del conocimiento, no había tal cosa como un conocimiento corto placista o fugaz, sino más bien algo duradero en el tiempo. Y efectivamente, el conocimiento como lo entendían los griegos y desde Platón hasta Descartes, se basaba en la tradición, esto es, el conocimiento iniciado en el hombre desde que el mundo es mundo y más precisamente, desde que aquel empezó a poblarlo. De ahí el prestigio del conocimiento como tal, a saber, la herencia divina en los hombres, ante lo 
cual ellos solo tienen que recordar para traerlo de vuelta.

En el ahora, sin embargo, el recordar supone una actividad ociosa, fútil, infértil, pues desviaría la atención de lo mediato, de la experiencia personal, lo configurado para ser devorado en el instante, mas no para ser atesorado y posteriormente hacer uso de ello. De hecho, el conocer en el mundo contemporáneo ya no supone recordar o reconocer como lo entendía Platón, sino vivir el instante, tal cual lo describe Nietzsche y Bauman. La experiencia personal se configura en un mundo puntillista donde el instante es el pasado, el presente y el futuro. En otra clave, donde se elimina el anclaje a lo anterior y a lo futuro y se enclava en la inmediatez del ahora.

El tiempo puntillista está roto, o más bien pulverizado, en una multitud de "instantes eternos" eventos, incidentes, accidentes, aventuras, episodios - monadas cerradas sobre sí mismas, bocados diferentes, y cada bocado reducido a un punto que se acerca cada vez más a su ideal geométrico de no dimensionalidad" (Bauman, 2007, p. 52).

Ese efecto de no dimensionalidad es el provisto por las experiencias contemporáneas sensibles, llamémosle la anulación de un continuo de eventos más o menos coherente o proveniente uno del otro; esa aceleración de la que habla Bauman no es otra cosa que la imposibilidad de separar el pasado, el presente y el futuro, pues todo estaría condensado en un mundo enclavado a un presente absoluto y constante, alejado de recuerdos, de memoria, de flashbacks y de eternos déjà vu. En suma, el hombre del presente vive en un no tiempo y un no lugar, un anti ahora dominado por la dispersión del instante y lo inmediato, pues lo perecedero es su razón de ser, su fundamento sobre el cual él se asienta y a partir de ahí busca desenvolverse en el mundo.

\section{Posmodernidad, racionalidades y efectos de verdad}

Si quisiéramos aproximarnos a una definición cabal de verdad posmoderna, tendríamos primero que definir a la posmodernidad y hacerlo de manera honda, pues a menudo se le busca descalificar ensalzando los parámetros modernos, en vez de empezar por aquilatar la vigencia de sus planteamientos, echar un vistazo a lo que sucede a nuestro alrededor y leer a autores posmodernos.

Curiosamente aquello que caracteriza a la posmodernidad y, por lo cual ha sido duramente criticada, es precisamente su crítica feroz al pensamiento racional, cuya renuencia al cambio evita vientos democráticos que oxigenen, por lo menos, algunos pensamientos modernos ya caducos.

Antes que nada, contextualicemos el fenómeno posmoderno y para eso debemos remitirnos a mediados del siglo XIX y principios del XX. Eso nos lleva a pensar en cuatro autores claves, Freud, Marx, Nietzsche y Saussure. Cada uno, desde su respectiva disciplina, representó una propuesta alternativa a las entonces categorías existentes que explicasen la configuración del mundo. Entonces ellos básicamente describieron los mismos fenómenos a partir de definiciones novedosísimas, supieron encontrar aquello que la razón moderna a través de sus conceptos había dejado de lado. En otras palabras, identificaron entre las grietas de la modernidad las otras miradas que 
clamaban por salir, por manifestarse y de esa manera reinterpretaron el mundo, pero primero lo deconstruyeron. De ahí que las ideas de los autores antes mencionados tuvieran un gran impacto en el siglo XX y, más concretamente, en los autores llamados posmodernos como son: Deleuze, Foucault, Derrida, Lacan, Vattimo, Baudrillard, Bourdieu, entre otros. Y es que hay que decirlo, los primeros vaticinaron el mundo por venir, por eso muchas de sus propuestas aún son vigentes y fueron acogidas por los últimos.

Y el foco de estudio de esa nueva generación de intelectuales viró hacia las Artes y Humanidades. Así, tenemos novelas, poemas, películas, pinturas, fotografías, cuentos y obras de teatro como soportes privilegiados estudiados por ellos. Naturalmente el cuestionamiento no se hizo esperar. En primer lugar, dichos autores no tendrían una base filosóficamente epistémica comparable a los pensadores modernos y, segundo, el eclecticismo de sus reflexiones despertaba sospechas inevitables.

Es decir, se les buscó descalificar a partir del cuestionamiento de la materia de sus análisis pues estos no eran equidistantes con lo que una razón cartesiana hubiera podido dar lugar. Por eso a priori una mirada tradicional, racionalmente moderna, condena el menor atisbo de insurrección a los límites desde antiguo establecidos por ella misma. Entonces debemos hablar de una serie de arquetipos erigidos para controlar, sistematizar y circunscribir el conocimiento, a saber, lo real, la realidad, el sujeto, el ser, la subjetividad y, desde luego, la verdad.

La verdad se la buscó constreñir tradicionalmente a un sistema binario, verdadero - falso, dentro - fuera, bueno - malo, correcto - incorrecto, arriba - abajo. Y de esa manera se soslayaron las posibilidades que no caían dentro de ese binarismo no de circunvoluciones rizomáticas, sino de dualismos desde ya preconcebidos en su origen y en esa medida limitantes. Los entrecruces de sus posibilidades fueron vistas como zonas muertas, estériles, insospechadamente dudosas. No obstante, el aporte evidente que representa y erige una mirada transdisciplinaria.

Otro aspecto a mencionar es la supuesta imposibilidad de referirse a una sociedad posmoderna en tanto aún estaríamos inmersos, por lo menos de este lado del mundo, en un modelo moderno insipiente, incluso en ocasiones pre-moderno. Lo cierto es que quienes afirman tal cosa han quedado flotando dentro del fantasma moderno y no quieren dejarlo ni pueden hacerlo y naturalmente ignoran las nuevas reglas de juego, esto es, las características que han replanteado el orden mundial dando origen a uno nuevo. Ellas son: globalización, economía, consumismo, medios masivos, tecnología y bienes culturales compartidos. A su vez, los últimos contienen todos los primeros, pues cuando hablamos de bienes culturales compartidos, nos referimos al uso y al consumo común de libros, series de $\mathrm{tv}$, películas, música, revistas, portales de internet, redes sociales, restaurantes de comida rápida y herramientas tecnológicas.

Vale decir que esta nueva configuración del mundo pone en jaque las clásicas definiciones binarias y tradicionales propias de la modernidad, recordemos que ésta se caracterizó por buscar la independencia del hombre frente al mundo, los aires de libertad y autonomía caracterizaron, en buena cuenta, al siglo XVIII, siempre abocado y circunscrito a lo rural, a su realidad inmediata. No obstante, no bien entrado el siglo XIX, los aires de liberación 
tuvieron que hacer frente a la aparición de la metrópoli, a propósito de la crisis existencial del hombre, a saber, el no poder no vivir sino fragmentado y la imposibilidad ya no solo de ser independiente, sino de ser en esta diáspora global.

En otras palabras, los pensadores modernos se centraron en la vida del campo de Europa o zonas aledañas necesariamente parecidas a ella, no previeron los cambios que suponen la magnificación de la ciudad y las interconexiones entre ésta con otras similares en diferentes continentes, como tampoco las implicancias del sobre dimensionamiento de la experiencia y lo múltiple de ésta en la vida del hombre. Y es este pensamiento el contexto de la posmodernidad, la diferencia es que a la metrópoli vaticinada por Simmel, que ya es una realidad, habría que añadirle las metrópolis virtuales que obligan al hombre a definirse, a ser, a bifurcarse constantemente, independientemente de toda experiencia previa. En suma: una (re) definición constante del hombre y lo que experimenta día a día.

A su vez, los nuevos ejes temáticos simplemente vienen a reflejar el desgaste del predominio occidental dentro del panorama mundial, desplazando de esa manera a lo general e historicista y dando pie a lo particular y a las historias individuales y de esa manera diluyendo todas las fronteras de tiempo y espacio que una racionalidad moderna solía reflejar y tanto se opuso en flexibilizar.

Salta a la vista luego, dentro de ese panorama, la definición de la verdad, es decir, la verdad dentro del mundo contemporáneo. Empecemos diciendo que no existe una definición de la verdad dentro de la posmodernidad, pero sí podemos aproximarnos a una posible definición, en base a las categorías que manejan algunos autores, entre ellos los llamados posmodernos y de lo que ellos se ocupan.

Y a propósito de eso recordemos lo que Gilles Deleuze junto a Claire Parnet escribió en el libro Diálogos, a saber, la sacrosanta alianza existente entre filosofía, historia y pensamiento en torno al poder.

La historia de la filosofía siempre ha sido el agente de poder dentro de la filosofía, e incluso dentro del pensamiento. Siempre ha jugado un papel represor: ¿cómo queréis pensar sin haber leído a Platón, Descartes, Kant y Heidegger, y tal o cual libro sobre ellos? Formidable escuela de intimidación que fabrica especialistas del pensamiento, pero que logra también que todos los que permanecen fuera se ajusten tanto o más a esta especialidad de la que se burlan. Históricamente se ha constituido una imagen del pensamiento llamada filosofía que impide que las personas piensen. (Deleuze, 1997, p. 17)

En efecto, esa dictadura del conocimiento ha dominado buena parte del pensamiento occidental y mundial, constriñendo los límites de sus categorías, colocándolas al servicio de un discurso único, tornando dócil y servil las ideas y volviendo tales cualesquiera otras propuestas que diverja de las primigenias.

Al respecto Pierre Bourdieu, filósofo y sociólogo francés dice lo siguiente:

A partir de la segunda mitad del siglo XIX, la filosofía europea se ha definido constantemente a sí misma en oposición a las ciencias 
sociales, contra la sociología y la psicología en particular, y a través de ellas contra cualquier forma de pensamiento que esté, explícita e inmediatamente dirigido a las realidades "vulgares" del mundo social. La negativa a desmerecerse por estudiar objetos considerados inferiores o por aplicar métodos "impuros", ya sea el examen estadístico o el simple análisis historiográfico de documentos, impugnado una y otra vez por los filósofos como "reduccionista", "positivista", etc., va de la mano de la negativa a zambullirse en la fugaz contingencia de las cosas históricas que mueve a esos filósofos más interesados en su dignidad estatuaria a retornar siempre (...) a los pensadores más "universales" y "eternos". (2005, p. 224).

Ese supuesto desprestigio del que gozan los que no se dedican a la filosofía dura o, lo que es lo mismo, evitan avocarse a temas fundamentales filosóficamente hablando y en vez de eso se orientan a cuestiones mundanas, ajenas del quehacer filosófico tradicional, poco o nada aportan en la pleitesía esperada de toda empresa filosófica dirigida a priori a cuestiones de carácter prioritario y en esa medida de mayor valía. Se trata en buena cuenta de reincidir y redundar sobre las investigaciones ya hechas y sobre el estudio de los mismos autores harto estudiados bajo el pretexto de una nueva relectura o de un enfoque novedoso.

Y según Loïc Wacquant, el mismo filósofo Bourdieu plantea lo siguiente:

La filosofía padece una incapacidad para resolver la antinomia de historicidad y verdad por otros medios que las lecturas exegéticas que actualizan obras pasadas de tal manera que niegan más o menos la historicidad. Las soluciones a esta antinomia propuestas por Hegel (la dialéctica que persevera y trasciende), Kant (la construcción retrospectiva de las filosofías pasadas) y Heidegger (la develación de la revelación originaria) convergen en su rechazo de la historia. (Bourdieu, 2005, p. 225)

En efecto, el empecinamiento del filósofo por rechazar cuestiones actuales y priorizar, en cambio, obras exegéticas denota claramente cierta tendencia a no querer afrontar dilemas actuales. En trabajar, irónicamente, al margen de la historia o sobre la historia, entendido esto último como una capa paralela yuxtapuesta sobre lo que ocurre por debajo y que los autores de manera clara y directa ignoran o pretenden desconocer.

Precisamente, todo lo anterior se instala dentro de un campo contrario al libre ejercicio intelectual que pudiera dar pie a una verdadera búsqueda de conocimiento en su más diversa índole. Recordemos que tradicionalmente el poder ha sido asociado al fenómeno de la represión, vale decir, el poder se ejercería a través de la restricción, pero esa definición es bastante jurídica. Una idea distinta supondría concebir al poder como el flujo constante de efectos de poder. De igual modo, la idea de la verdad es limitante, toda vez que, dentro de los discursos mismos, históricamente hablando, se debe identificar no en qué medida algo es verdadero o falso, sino sus efectos de verdad o falsedad. Naturalmente, eso supondría desplazar también la idea de un sujeto y una historia y priorizar sujeto e historia imbricados, de lo contrario nos alejaríamos de la 
cuestión genealógica y nos acercaríamos a un sujeto y a una historia ideales. En el decurso de los discursos queda en evidencia el amalgamiento entre los actores sociales y su circunstancia histórica. En consecuencia, todo análisis de la verdad supondrá ese flujo constante; la circulación de los efectos de lo verdadero y de lo falso.

Y es el propio Foucault quien afirma el carácter indisociable de verdad y poder, pero no a la manera de algo que la controle, aunque en la práctica pudiera darse el caso, sino como flujo constante, las acciones y reacciones del poder:

La verdad no está fuera del poder ni sin poder (no es a pesar de un mito del que habría que recoger la historia y sus funciones, la recompensa de los espíritus libres, el hijo de largas soledades, el privilegio de los que han sabido liberarse). La verdad es de este mundo; se produce en él gracias a múltiples coacciones. Y detenta en él, efectos regulados de poder. Cada sociedad tiene su régimen de verdad, su "política general" de la verdad: es decir, los tipos de discurso que acoge y hace funcionar como verdaderos o falsos, el modo como se sancionan unos y otros; las técnicas y los procedimientos que están valorizados para la obtención de la verdad; el estatuto de quienes están a cargo de decir lo que funciona como verdadero. (Foucault, 1987, p. 187)

Luego, la verdad concebida entonces como un acuerdo de comunidad, corpus de ideas funcionales para los propósitos que ella juzgue conveniente. Y todo lo que ello suponga, a saber, los criterios de medición y recolección de la verdad, así como los encargados de determinarla como tal, es decir, los veedores y veladores de la verdad.

Estaríamos pues frente a un aparato construido ex profeso para ejercer el flujo de la verdad, su control y diseminación, definiendo de esa manera sus usos y desusos, como también a los artífices y las prácticas circunscritas a los límites establecidos por los encargados de llevarla a cabo de manera efectiva.

Cierto es que las definiciones entre filósofo y filósofo pueden variar, algunas ser más extremas y radicales que otras, pero lo cierto es que ellas mismas representan ya un intento de acercarse. Y en el caso de Nietzsche, llamémosle el primer filósofo posmoderno, o que por lo menos influyó en esa corriente de pensamiento, su antidefinición de verdad, en tanto contraria a las definiciones ofrecidas por los griegos, posteriormente medievales y finalmente modernos, subyace a todas las esgrimidas por los filósofos posmodernos. A saber, el componente de subjetividad, e incluso, la imposibilidad de ser objetivamente subjetivo.

Contra el positivismo, que se queda en el fenómeno "sólo hay hechos", yo diría, no, precisamente no hay hechos, sólo interpretaciones. No podemos constatar ningún factum "en sí": quizás sea un absurdo querer algo así. "Todo es subjetivo", decís vosotros: pero ya eso es interpretación, el "sujeto" no es algo dado sino algo inventado y añadido, algo puesto por detrás. - ¿Es en última instancia necesario poner aún al interprete detrás de la interpretación? Ya eso es invención, hipótesis. (Nietzsche, 2008, p. 222)

Entender así la verdad, supondría una verdad, si cabe el término, elástica, 
maleable, inacabable, pero también una razón acorde a ella y no viceversa, es decir, las racionalidades que se adecúan a los efectos de verdad. De ahí la propuesta de proponer racionalidades que impactan, se unen y se separan, se fusionan y se friccionan, creando un efecto rebote que las eyecta de afuera hacia adentro y de adentro hacia afuera, lejos de las lógicas tradicionales y de una razón tradicional. Más cerca de una caída constante, de un usufructuar lo hallado, que de categorizar arbitrariamente y a priori, las condiciones de algo que deviene y por eso mismo, nunca se detiene. Por eso, la experiencia de la verdad no podría ser otra que, y a riesgo de ser arbitrarios, la distensión de posibilidades, la creación consciente o inconsciente de efectos de verdad, verosimilitudes varias, cuya raíz ya nacería dispersa, inestable, multiforme, heredera de híper-manifestaciones, nunca de silencios, encuentros y desencuentros, conflictos y desacuerdos, siempre abierta a la reproducción de nuevos juegos y representatividades.

Sin embargo, el filósofo híper racionalista se mira al espejo de sus propias reflexiones y crea un modelo o filtro racional a partir de ellas, lo que él cree puede tender a lo racional y a lo objetivo. Así, crea un modelo, en esa medida, limitado por su propia concepción y espera encontrar en el mundo la coincidencia con sus planteamientos. Digamos entonces que el filósofo circunscribe el conocimiento a las teorías y modelos que él elabora y espera contengan y confirmen la información del mundo. Es decir, crea una serie de arquetipos sobre el conocimiento y el mundo, que espera coincidan, pero donde el primero tiene primacía sobre el segundo, de tal manera que el segundo esté contenido en el primero. Así, la objetividad del conocimiento se construye y con ella la objetividad del mundo y la objetividad del conocimiento del mundo, también.

La verdad, luego, al igual que toda idea proveniente de una razón moderna y reverberada en el deseo de seguir controlando el conocimiento a través de modelos contemporáneos, necesariamente imaginada, respondería a un (re)construir necesario que lleva implícito una (de) construcción previa también sine qua non; hay que aceptarlo, el ejercicio de recordar trae a colación (re)cortar y pegar información, en otras palabras, el recordar es editar, metamorfosear, mutar los datos en algo distinto que solo tenemos la certeza de conservar su naturaleza de maleable. Entonces pensar en definir lo indefinible por naturaleza ya es una proeza heroica, expresar lo (in) expresable, definir lo (in)definible, detener lo oscilante, son ejercicios todos vanos, aunque constantes y necesarios. Pues hacia ahí se orienta el espíritu humano del conocimiento, en saber y conocer, pero primero en definir lo que está en constante movimiento ¿Es posible entonces detener lo constantemente movible o definir lo que debido a su propia naturaleza no puede ser definido? ¿Cómo expresar lo que se encuentra escurridizo o se esconde entre las grietas de la forma? ¿Existe acaso un lenguaje apropiado que exprese lo (in) expresable? ¿Cómo podemos hacer para (des)ocultar lo que la palabra oculta? Y en ese sentido ¿de qué nos interpela el silencio? O mejor aún ¿qué exclama el silencio cuando calla?

Finalmente, ya hemos visto el empecinamiento de la modernidad al querer adjudicarle una verdad objetiva al sujeto, podemos agregar al respecto lo volátil que resulta todo esfuerzo iniciático que tome como punto de partida una instancia denominada sujeto ligada inexorablemente a lo único e individual 
en tanto universal, es decir, lo que todos tendríamos como denominador común por el simple hecho de ser tales. Esa postura, aunque resulte obvio decirlo, parte desde la indivisibilidad y el carácter unívoco o, por lo menos, de lo más cercano que se le parezca. Es así que posteriormente un positivismo lógico, un aparato científico de la mano de las matemáticas, se arrogan el derecho de establecerse sobre un sitial de conocimiento, pseudamente llamado objetivo y objetivante. Tomar por sentado tales presupuestos, creemos, fue y ha sido la gran tara de la modernidad y probablemente el lugar donde deberían gestarse gran parte, sino todos los debates contemporáneos, en tanto punto de partida. De ahí que nuestro planteamiento cobre suficiente relevancia, a saber, una crítica lapidaria hacia esa imaginaria neutralidad y univocidad del sujeto.

Es una fantasía seguir creyendo que Descartes tuvo la razón respecto al carácter univoco del sujeto, y más precisamente del yo. Basta mirar a nuestro alrededor para comprobar fehacientemente lo vago y endeble de su propuesta, corroborando así que es el cuerpo más que el yo el gran depositario del cúmulo de múltiples, dispares e inconstantes posibilidades. Por un lado, la idea del yo resulta limitante tal cual la plantea el filósofo francés y por otro, la arbitrariedad y literalidad que los intérpretes han deducido a partir de ella. En efecto, la idea de un yo eterno, racional, universal, único e indivisible se ha desmoronado no bien entrado, por lo menos, el siglo XX y ha encontrado y evidenciado su fracaso absoluto en la segunda mitad. Entonces, una filosofía más flexible hubiese podido vislumbrar no la fijeza del yo, sino su transitoriedad, pues el yo transita de un lado al otro, definiendo una órbita variopinta y evidenciando así, no uno, sino varios yoes simultáneos y estratificados, es decir, lo imposible de imaginar un yo aislado, Nietzsche agregaría un cuerpo, incólume e imperecedero que los griegos y la modernidad se han empeñado tanto en hacernos creer. El error de los filósofos, luego, ha sido el literalizar la palabra yo, en vez de tomarla como un elemento meramente transitorio y en esa medida intercambiable y movible.

En el acto voluntario, se añade de este modo al placer de dar una orden, el placer del instrumento que lo ejecuta con éxito; a la voluntad se añaden voluntades "subalternas", almas subalternas y dóciles, pues nuestro cuerpo no es más que el edificio colectivo de muchas almas. El efecto soy yo; aquí sucede lo que sucede en toda colectividad feliz y bien organizada: la clase dirigente se identifica con los éxitos de la colectividad. En todo querer se trata simplemente de mandar y de obedecer dentro de una estructura colectiva, compleja, integrada, como he dicho, de "muchas almas". (Nietzsche, 1974, p. 416)

De la reflexión tan aguda de Nietzsche podríamos decir que el yo que vemos y donde se deposita la verdad es un efecto de superficie, es decir, lo más palpable, lo inmediato, la primera opción, y como tal debiera ser descartada. Habría pues una apariencia individual del yo, él se presentaría y manifestaría en tanto que individual, cuando en realidad solo se trataría un recubrimiento, pues ese cascarón albergaría lo múltiple. Desafortunadamente la filosofía ha interpretado y asociado tradicionalmente el yo a lo individual y lo plural a lo colectivo, mutilando y castrando la posibilidad de, por ejemplo, concebir 
una multitud individual y de individuos múltiples.

Pero el asunto no queda allí, la situación se complica más al creer que somos nosotros al decir, por ejemplo, yo creo, quienes tenemos poder de decisión sobre el pensamiento, y no que él es independiente de venir o llegar, al margen de que nosotros lo convoquemos o no.

A saber, que un pensamiento viene cuando "el" quiere y no cuando "yo" quiero, de tal suerte que es falsificar los hechos decir que el sujeto "yo" es la determinación del verbo "pienso". Algo piensa, pero que eso sea precisamente el antiguo e ilustre "yo", eso no es más que, para decirlo en términos moderados, una hipótesis, una alegación, pero no ciertamente una "certidumbre inmediata". En fin, ya es demasiado decir que algo piensa, pues ese "algo" contiene ya una interpretación del proceso mismo. (Nietzsche, 1974, p. 414)

Como vemos, el reclamo de Nietzsche y que nosotros compartimos es el arrogamiento de la filosofía y de la ciencia de antropocentrizar lo circundante, como si fuese exclusividad del hombre el proceso de formular la experiencia o materializarla en una proposición, de tal manera que recién entonces posea validez, cerrando la puerta a otras posibilidades que podrían, entre otras cosas, desclasar al enunciador de su sitial, en otras palabras, quebrar la relación necesaria entre él y el enunciado.

Podría invertirse la relación y empezar desde las frases y las oraciones y en qué medida éstas ya contienen al sujeto de la enunciación o, en su variante, que son ellas quienes interpelan y liberan, momentáneamente, la sujeción de la que el sujeto es objeto, pero que él codifica equivocadamente como cierta independencia y predominio sobre lo que enuncia.

Existe, además, la neutralidad tantas veces esgrimida, aunque no denominada de esa manera, del analista sobre lo que describe, una forma de poner en evidencia su poder absoluto, el terreno de sus dominios, por encima del resto, de toda reacción posible o influencia que pueda surgir del contacto en la relación sujeto objeto, como si fuese realmente posible aislar al objeto del sujeto y al sujeto del objeto. Y tal vez valga la pena recordar, en ese sentido, lo imposible de tal empresa, y nuevamente el deseo del hombre de lo contrario, merced al izamiento clásico de la bandera del poder ejercer poder.

Hay aún inofensivos habituados a la introspección que creen que existen "certidumbres inmediatas" por ejemplo el "yo pienso" o, como era la creencia supersticiosa de Schopenhauer, el "yo quiero"; como si en este caso el conocimiento consiguiese aprehender su objeto pura y simplemente en tanto que "cosa en sí", sin alteración del lado del sujeto ni del lado del objeto. (Nietzsche, 1974, p. 413)

Las experiencias son un continuo incesante, el aprendizaje y el aprehender información hacen pensar más en circulación que en algo estático. Lo mutante es lo que caracteriza todo proceso de adquisición, el devenir constante del sujeto en objeto y del objeto en sujeto o, por lo menos, la (re)composición de las partes, desclasando una psicología de la Gestalt, pues la parte es el todo y el todo es la parte; son los intersticios, olímpicamente dejados de lado por la historia oficial, los que habría que 
analizar, los procesos de transformación desaparecidos y ausentes por la ceguera occidental y la falsa creencia en entidades (in)móviles, cuando de lo que se trata es de reflejar no las constancias, sino las (in) constancias de la norma, el reinado de las excepciones y las pequeñas historias, lo genealógico y no lo teleológico, los devenires de los usos y los usos que devienen. No perdamos de vista que todo está en tránsito, en proceso de, en vías de y hoy más que nunca las contrariedades y las antonimias refulgen ya no solo en la oscuridad de los que se han empeñado en extinguirlas, los modernos, sino en derredor nuestro, en el ahora, en la instantaneidad de cada momento que los fenómenos contemporáneos han impreso en el hombre y éste reaccionado a ellos y no viceversa.

Ahora bien, más que de sujeto, habría que hablar de identidad, concepto sociológico, y más que de identidad, habría que hablar de consumidor. En efecto, en la actualidad poco importa los orígenes, el background da cada uno, el saber minoritario, lo que cuenta es lo que eres y lo que eres es lo que consumes, la ropa que llevas puesta, la marca del auto que conduces y los lugares que frecuentas. Luego, manejar una cuatro por cuatro, por citar un ejemplo, te coloca en una suerte de sitial desde el cual mirarás en picado el mundo, al otro, a los demás. El de al lado, luego, es inferior a ti, se halla en una situación de subordinación.

Se bombardea a consumidores de ambos sexos, de todas las edades y extracciones, con recomendaciones acerca de la importancia de equiparse con este o aquel producto comercial si es que pretenden obtener y conservar la posición social que desean, cumplir con sus obligaciones sociales y proteger su autoestima, y que a la vez se los reconozca por hacerlo. Esos mismos consumidores se sentirán incompetentes, deficientes e inferiores a menos que puedan responder prontamente a ese llamado. (Bauman, 2007, p. 81)

\section{A manera de conclusión}

Como vemos, atrás quedaron los tiempos de seguir a pie juntillas la noción de sujeto, en vez de eso surge la necesidad de ser consumidor, el deseo imperioso de darle cierta consistencia a nuestras tristes, melancólicas y depresivas vidas. Pues el efecto de ser consumidor es el de hundirse en la tristeza, luego de lo exacerbante que resulta excederse en las compras viene el declive, el camino cuesta abajo de asimilar que lo que se ha comprado poco o nada aporta a nuestras miserables vidas, que todo es etéreo y sin solución y que, irónicamente, el único escape es la vorágine del consumo. Es decir, seguir consumiendo. Ser consumidor, luego, es el nuevo carné de identidad, el ADN de cualquier ciudadano promedio en la diáspora actual.

De esta manera queremos vulnerar la aún confianza depositada por algunos académicos y autores en una supuesta verdad entrañable e inamovible, como en una razón absoluta, que más parece responder a un lamento de su propia inoperancia en el mundo actual, que a un análisis concienzudo y profundo de nuestros tiempos.

\section{REFERENCIAS BIBLIOGRÁFICAS}

Bauman, Z. (2007). Vida de consumo. México, D.F.: Fondo de Cultura Económica. 
Bourdieu, P. (2005). Una invitación a la sociología reflexiva. Buenos Aires: Siglo XXI Editores.

Deleuze, G. (1997). Diálogos. Valencia: Pre-textos.

Foucault, M. (1987). Un diálogo sobre el poder y otras conversaciones. Madrid: Alianza Editorial S.A.

Foucault, M. (2012). La hermenéutica del sujeto. Curso en el College de France (1981-1982). México, D.F.: Fondo de Cultura Económica.

Hevia, J. (2016). Del dicho al hecho. Vigencia y desgaste del saber proverbial. Lima: Aguilar.
Lyotard, J. (2004). Qué era la posmodernidad. En: Casullo, Nicolás, comp., El debate modernidadposmodernidad. Buenos Aires: Retorica Ediciones.

Nietzsche, F. (1974). Más allá del bien y del mal. Madrid: E.D.A.F.

Nietzsche, F. (2008). Fragmentos Póstumos IV (1885-1889). Madrid: Tecnos.

Popper, K. (1994). Conjeturas y refutaciones. Barcelona: Paidós.

Sibilia, P. (2017). La intimidad como espectáculo. Buenos Aires: Fondo de Cultura Económica, S.A.

Recepción: 07-09-2019

Aceptación: 01-10-2019 